\title{
Emprego formal na indústria têxtil catarinense: localização, caracterização, diferenças e semelhanças entre as mesorregiões
}

\author{
Luís Abel da Silva Filho* \\ Silvana Nunes de Queiroz ${ }^{* *}$
}

\begin{abstract}
RESUMO - O artigo tem como objetivo avaliar a dinâmica da indústria têxtil catarinense, comparando o perfil dos postos de trabalho nas mesorregiões do estado, a partir do processo de reestruturação produtiva dessa indústria. Utilizou-se, para análise empírica, o banco de dados da Relação Anual de Informações Sociais (RAIS) e o Cadastro Geral de Empregados e Desempregados (CAGED) do Ministério do Trabalho e do Emprego (MTE), além de uma revisão literária acerca das transformações estruturais da indústria têxtil brasileira e catarinense. Os principais resultados indicam diferenças destoantes entre as mesorregiões. O Norte Catarinense, mesmo com menor participação do emprego têxtil no estado, mostrou melhor perfil nos postos de trabalho. Já a mesorregião Serrana, além de ter a menor participação percentual de postos de trabalho na indústria têxtil catarinense, mostrou ocupações mais precárias do que o observado no restante do estado. Cabe destacar que a qualidade do emprego formal no setor têxtil em todo o estado catarinense segue a dinâmica observada na indústria de transformação tradicional em todo o país a partir dos anos 1990.
\end{abstract}

Palavras-chave: Indústria têxtil. Emprego formal. Mesorregiões catarinenses.

\section{INTRODUÇÃO}

A abertura econômica brasileira nos anos 1990 desencadeou transformações em diversos setores da indústria nacional. Atividades mais tradicionais tiveram que adaptar-se aos novos padrões de produção mundial para manterem-se competitivas. Nesse processo assistiuse ao fechamento de inúmeras indústrias tradicionais instaladas no país, por estarem obsoletas para a competitividade tanto no mercado interno quanto no externo.

A indústria têxtil brasileira é considerada uma das mais antigas atividades industriais instaladas no país. Em seu processo recente de modernização - duas últimas décadas do século XX - várias transformações ocorreram tanto na inovação do seu processo produtivo quanto na distribuição espacial dessa atividade econômica. A reestruturação produtiva do final do século XX dimensionou e orientou os novos rumos tomados pela indústria têxtil brasileira em todos

\footnotetext{
* Mestre em Economia pela Universidade Federal do Rio Grande do Norte. É pesquisador do Observatório das Metrópoles da Universidade Federal do Rio Grande do Norte. Endereço eletrônico: abeleconomia@hotmail. com.

** Doutoranda em Demografia pelo Núcleo de Estudos de População da Universidade Estadual de Campinas. É professora assistente do Departamento de Economia da Universidade Regional do Cariri. Endereço eletrônico: silvanaqueirozce@yahoo.com.br.
} 
os seus segmentos.

O processo de reestruturação produtiva vivenciado pelas indústrias brasileiras teve reflexos importantes sobre as atividades trabalho-intensivas. A indústria têxtil, notoriamente reconhecida como grande geradora de postos de trabalho, passou por transformações que causaram ônus excessivamente elevado à mão de obra atuante nesse segmento. A tecnologia de ponta adotada em seu processo produtivo lhe permitiu maior competitividade no mercado externo. Contudo, esse segmento passou a caracterizar-se como capital-intensivo, ao provocar uma série de consequências para a força de trabalho têxtil do país (KON; COAN, 2004; SILVA FILHO; QUEIROZ, 2010).

$\mathrm{Na}$ verdade, todos os segmentos da indústria de transformação brasileira notificaram problemas de ordem estrutural que foram traduzidos para o mercado de trabalho. A escolha do segmento têxtil para essa investigação, assim como o estado de Santa Catarina, justifica-se em função de que, em 2009, 26,63\% dos postos de trabalhos formais da indústria de transformação do estado estavam nesse setor, sendo ele o maior empregador direto. Além do mais, esse estado possui a segunda maior concentração de indústrias do setor têxtil do Brasil (8.698 unidades produtivas), sendo o segundo maior empregador em âmbito nacional (RAIS/MTE, 2009), gerando uma receita de US\$263 milhões em 2008 (FIESC, 2009).

O objetivo desta pesquisa é investigar as características socioeconômicas dos empregados no setor têxtil e a localização espacial dessa atividade segundo as mesorregiões catarinenses. Para tanto, a base de dados utilizada foi o CAGED e a RAIS, ambas do MTE.

O artigo está estruturado da seguinte forma: além das considerações iniciais, a segunda seção apresenta a evolução na geração de empregos na indústria têxtil catarinense; a terceira destaca os resultados da dinâmica do mercado de trabalho têxtil catarinense, segundo suas mesorregiões; por último, são feitas as considerações finais.

\section{EVOLUÇÃO NO SALDO DE EMPREGOS NA INDÚSTRIA TÊXTIL CATARI- NENSE}

O processo de reestruturação pelo qual passou a indústria brasileira, sobretudo aquela dos setores mais tradicionais, promoveu mudanças significativas nos padrões de produção. A inovação tecnológica permitiu o aumento da produtividade do trabalho, sem expansão correspondente das plantas industriais e da absorção da mão de obra que fora expulsa por tal processo (SILVA FILHO, 2010b).

Os dados no Gráfico 1 mostram que o saldo líquido de vagas no setor têxtil, mesmo em Santa Catarina, estado de grande dinamismo dessa atividade, mostrou-se negativo entre 
1996 e 1998, tornando-se positivo a partir de 1999.

GRÁFICO 1 - CRIAÇÃO LÍQUIDA DE POSTOS DE TRABALHO NA INDÚSTRIA TÊXTIL CATARI-

NENSE - 1996-2009

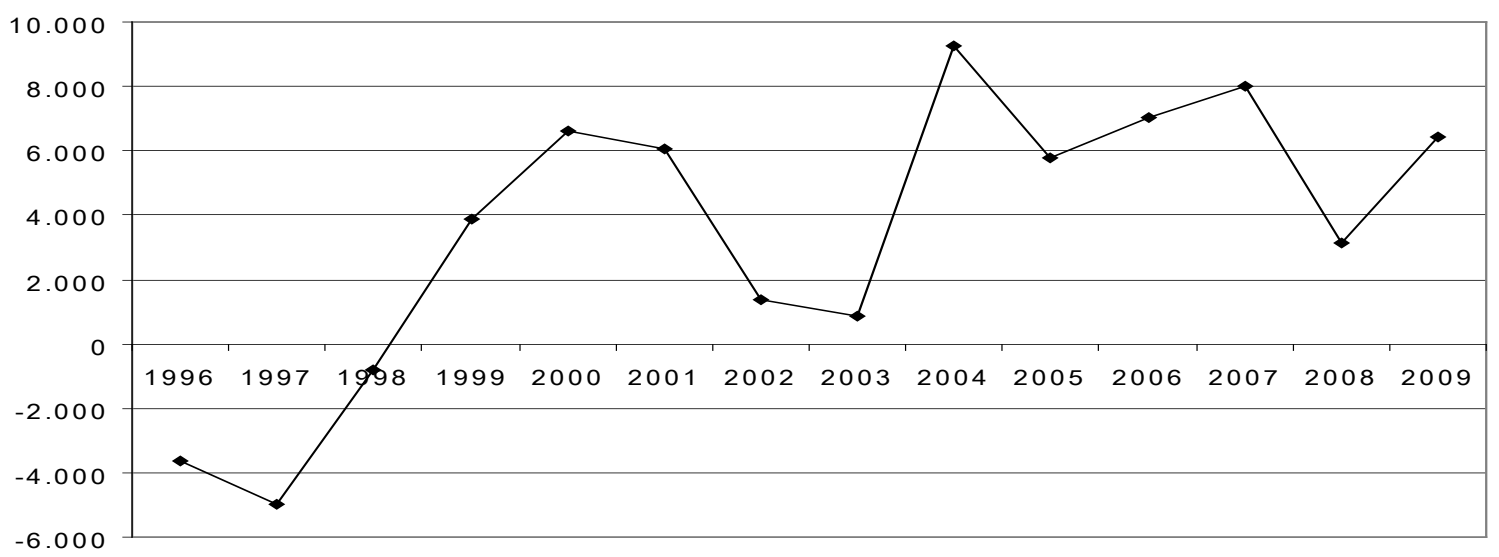

FONTE: Elaboração própria a partir de dados do Cadastro Geral de Empregados e Desempregados (CAGEDMTE).

Nos anos de 1999 a 2001, constatou-se melhor desempenho do setor têxtil com relação à geração de postos de trabalho. Em 2000 foram criadas 6.612 novas vagas, sendo essa marca superada somente no ano de 2004. Todavia, ao longo do período em análise, observamse grandes oscilações na criação de empregos.

\section{RESULTADOS EMPÍRICOS PARA AS MESORREGIÕES CATARINENSES}

O processo de concentração de atividades produtivas em aglomeração industrial, como forma de redução de custos, é denominada, na literatura recente, de clusters ou de Arranjos Produtivos Locais (APLs). No caso de Santa Catarina, todo o estado tem demonstrado competências para o desenvolvimento da aglomeração e da produção têxtil.

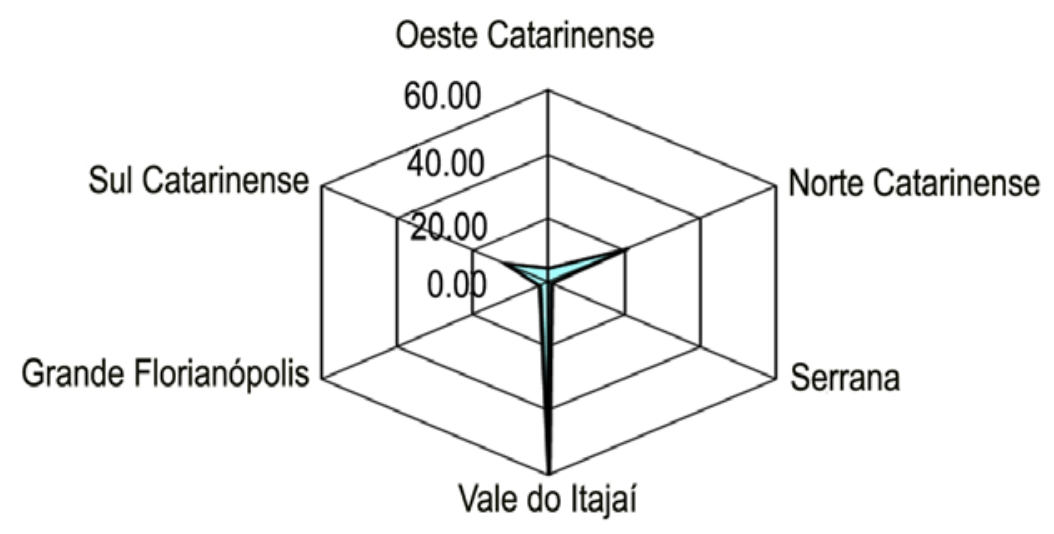

FONTE: Elaboração própria a partir de dados da Relação Anual de Informações Sociais - RAIS/MTE - 2009. 
No entanto, a mesorregião do Vale do Itajaí destaca-se, ao concentrar, sozinha, 59,98\% da mão de obra empregada no setor têxtil em 2009. O Norte Catarinense assume a segunda colocação, ao empregar 20,84\% dos trabalhadores. A Região Serrana demonstrou a menor aptidão para o desenvolvimento de tal atividade, ao criar somente $0,71 \%$ dos empregos.

Quanto à participação dos ocupados por porte do estabelecimento, 77,86\% dos trabalhadores na Grande Florianópolis e 72,54\% no Sul Catarinense estão empregados na indústria têxtil com até 99 funcionários.

GRÁFICO 3 - PARTICIPAÇÃO DOS OCUPADOS EM ESTABELECIMENTOS QUE EMPREGAM ATÉ 99 TRABALHADORES NA INDÚSTRIA TÊXTIL SEGUNDO MESORREGIÃO CATARINENSE - 2009

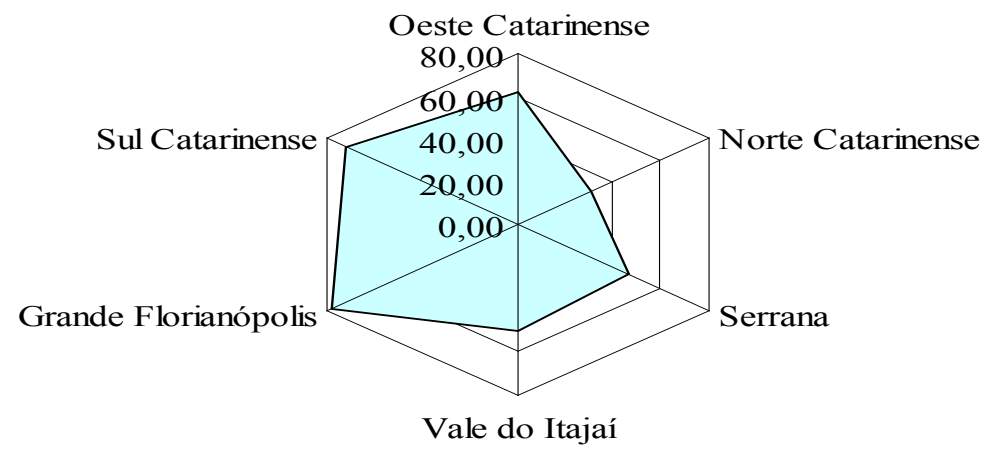

FONTE: Elaboração própria a partir de dados da Relação Anual de Informações Sociais - RAIS/MTE - 2009.

Por sua vez, no norte catarinense, $68,95 \%$ dos seus estabelecimentos empregam mais de 100 pessoas, seguidos por 53,26\% no Vale do Itajaí e 49,91\% na mesorregião Serrana.

GRÁFICO 4 - PARTICIPAÇÃO DOS OCUPADOS EM ESTABELECIMENTOS QUE EMPREGAM ACIMA DE 100 TRABALHADORES NA INDÚSTRIA TÊXTIL SEGUNDO MESORREGIÃO CATARINENSE - 2009

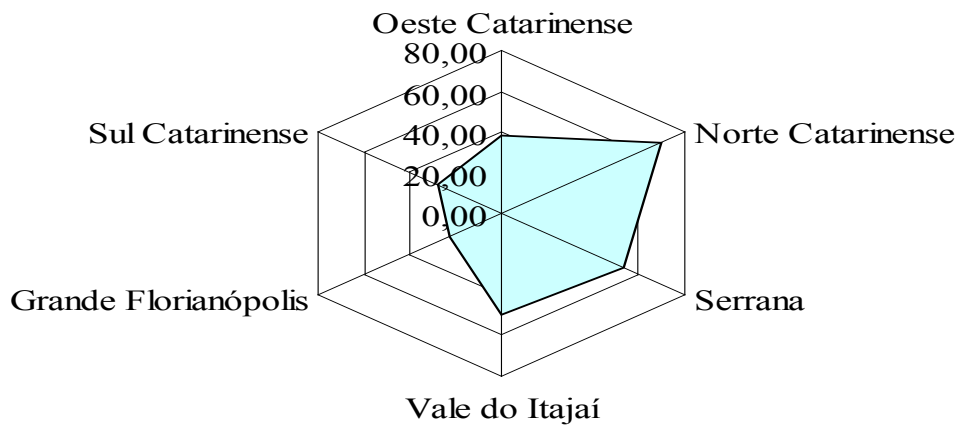

FONTE: Elaboração própria a partir de dados da Relação Anual de Informações Sociais - RAIS/MTE - 2009.

Quanto à idade dos ocupados, não se pretende inferir um padrão de qualidade do emprego, mas, somente, fazer a análise "eliminando" da base de dados aqueles muito jovens e idosos. Para fins desse estudo, quanto maior a concentração percentual de ocupados em cada 
uma das mesorregiões com idade entre o intervalo citado, melhor.

GRÁFICO 5 - PARTICIPAÇÃO DOS OCUPADOS COM IDADE ENTRE 25 E 65 ANOS NA INDÚSTRIA TÊXTIL SEGUNDO MESORREGIÃO CATARINENSE - 2009

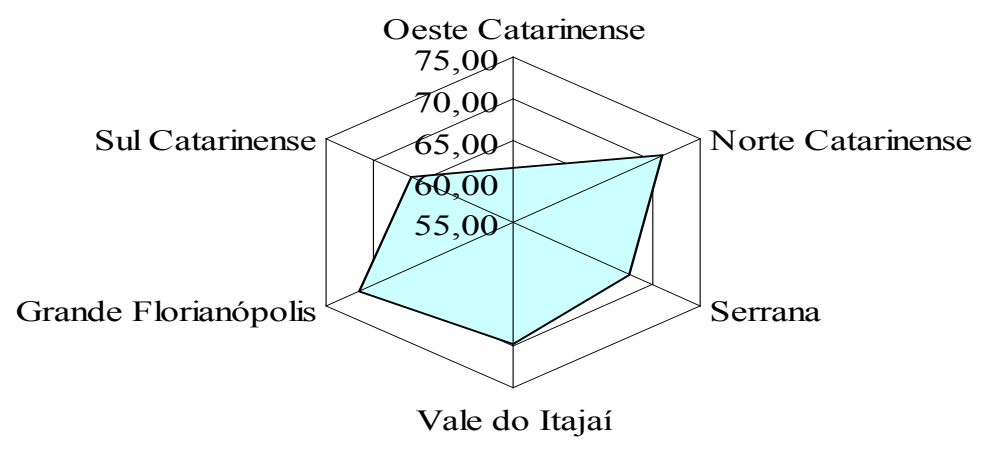

FONTE: Elaboração própria a partir de dados da Relação Anual de Informações Sociais - RAIS/MTE - 2009.

Por essa ótica, o Oeste Catarinense apresentou a menor participação percentual (61,69\%) de ocupados com idade entre 25 e 65 anos, e a mesorregião da Grande Florianópolis (71,40\%), seguida do Norte Catarinense (70,97\%), as maiores participações.

GRÁFICO 6 - PARTICIPAÇÃO DOS OCUPADOS COM ESCOLARIDADE A PARTIR DO ENSINO MÉDIO COMPLETO NA INDÚSTRIA TÊXTIL SEGUNDO MESORREGIÃO CATARINENSE - 2009

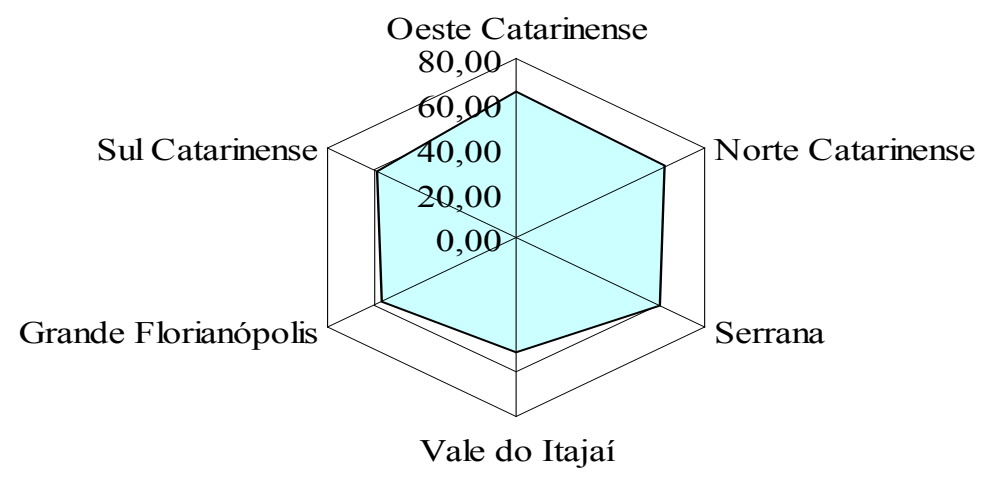

FONTE: Elaboração própria a partir de dados da Relação Anual de Informações Sociais - RAIS/MTE - 2009.

Com relação ao nível de escolaridade, foram considerados aqueles com pelo menos o ensino médio completo. Nesse quesito, observou-se desempenho um tanto satisfatório nas mesorregiões. O menor percentual de ocupados com ensino médio completo foi constatado na mesorregião do Vale do Itajaí (51,05\%), apesar de esta localidade possuir o maior número de ocupados na indústria têxtil catarinense. O melhor desempenho, por outro lado, ficou por conta do Oeste Catarinense, que registrou $65,60 \%$ da sua mão de obra com o ensino médio completo.

Quanto ao indicador de rotatividade, utilizou-se o percentual de ocupados que esta- 
vam em seus postos de trabalho há mais de 1 ano em 2009. A maior participação foi constatada na mesorregião Norte Catarinense (67,78\%) e o menor valor na mesorregião Serrana (51,61\%). As demais mesorregiões ficaram entre $58 \%$ e $65 \%$ de seu quadro de pessoal ocupado por mais de 1 ano.

GRÁFICO 7 - PARTICIPAÇÃO DOS OCUPADOS EMPREGADOS A MAIS DE 12 MESES NA INDÚSTRIA TÊXTIL SEGUNDO MESORREGIÃO CATARINENSE - 2009

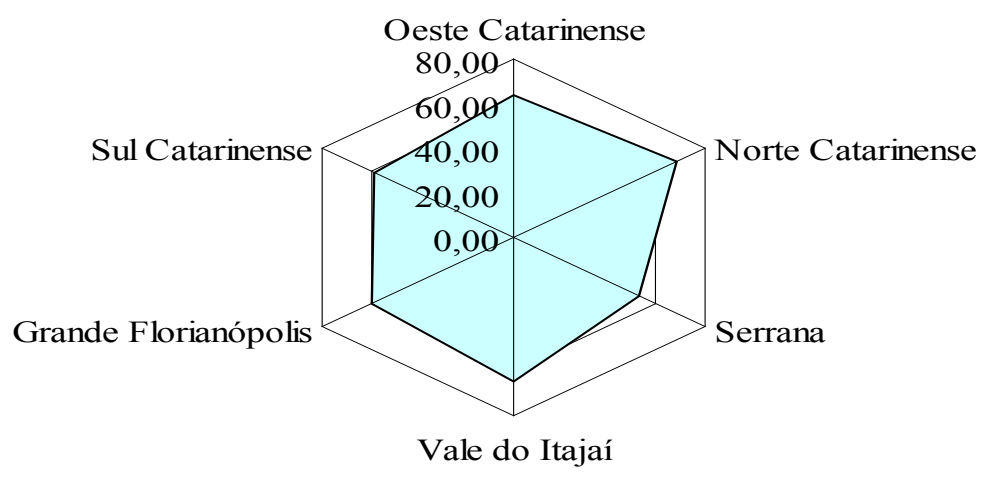

FONTE: Elaboração própria a partir de dados da Relação Anual de Informações Sociais - RAIS/MTE - 2009.

Silva Filho e Queiroz (2010a), em estudo para o setor têxtil do estado de Santa Catarina, já constataram elevada rotatividade empregatícia. Segundo os autores, 29,88\% dos ocupados na indústria têxtil catarinense em 1998 deixaram seus postos de trabalho em menos de 1 ano. Em 2008, observaram que esse percentual se elevou para 35,62\%. Assim, fica constatada a desestruturação do mercado de trabalho nos setores tradicionais da indústria de transformação, traduzida no setor têxtil catarinense.

GRÁFICO 8 - PARTICIPAÇÃO DOS OCUPADOS COM RENDIMENTOS SUPERIORES A DOIS SALÁRIOS MÍNIMOS NA INDÚSTRIA TÊXTIL SEGUNDO A MESORREGIÃO CATARINENSE - 2009

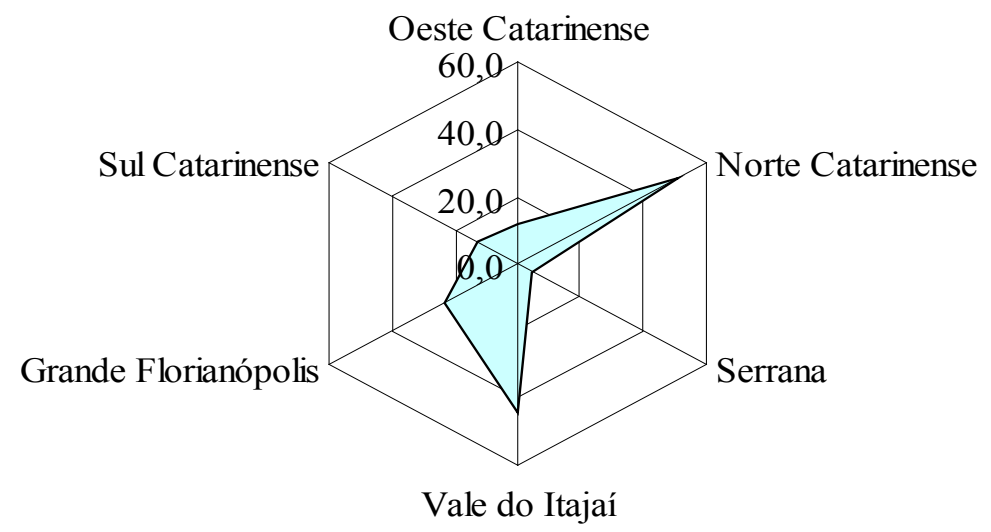

FONTE: Elaboração própria a partir de dados da Relação Anual de Informações Sociais - RAIS/MTE - 2009. 
Para fins de análise da remuneração dos ocupados na indústria têxtil, utilizou-se o percentual daqueles que auferiam rendimentos acima de dois salários mínimos. Nesse indicador, somente o Norte Catarinense registra percentual de ocupados acima de 50\% (50,60\%). No Vale do Itajaí, este valor atinge $44,10 \%$ dos ocupados e as demais mesorregiões ficaram todas abaixo da média do estado (39,60\%). Na Grande Florianópolis o valor foi de 23,20\%, no Sul Catarinense $13,30 \%$, no Oeste Catarinense $11,50 \%$ e por último a mesorregião Serrana, com apenas 4,30\% dos trabalhadores com rendimentos superiores a dois salários mínimos.

Chama atenção os baixos salários praticados no ramo têxtil catarinense e a diferença salarial entre as suas seis mesorregiões, já que esta é uma atividade econômica de grande representatividade para o estado.

\section{CONSIDERAÇÕES FINAIS}

Os resultados dessa investigação apontaram para a concentração do emprego formal têxtil na mesorregião do Vale do Itajaí. Essa localidade respondeu, sozinha, por aproximadamente $60 \%$ dos postos de trabalhos do estado de Santa Catarina. Por outro lado, a menor participação observada foi na mesorregião Serrana, ao gerar apenas 1\% de postos de trabalho no ramo têxtil.

No tocante ao porte dos estabelecimentos, a Grande Florianópolis concentrava aproximadamente $78 \%$ dos seus empregados em indústria com até 99 trabalhadores e o Norte Catarinense respondia por aproximadamente $69 \%$ dos ocupados na indústria têxtil com mais de 100 trabalhadores.

Além disso, foi no Norte Catarinense que se observou o maior percentual de ocupados com idade entre 25 e 65 anos, como também o maior percentual de trabalhadores com mais de 1 ano de trabalho (67,68\%). Já na mesorregião Serrana, somente 51,61\% permaneciam mais de 1 ano empregados. Cabe destacar que em todas as mesorregiões foram constatados elevados níveis de rotatividade.

Chamou atenção a mesorregião do Vale do Itajaí que, mesmo tendo a maior concentração de ocupados, registrou o menor percentual de trabalhadores com ensino médio $(51,05 \%)$. Nesse quesito, o Oeste Catarinense apresentou o melhor desempenho aqui observado $(65,60 \%)$. Todavia, quando se analisa a participação de ocupados com rendimento superior a dois salários mínimos, a região Serrana (4,30\%) apresenta o menor percentual e o Norte Catarinense (50,60\%) o melhor desempenho.

Por fim, fica evidente o desgaste do mercado de trabalho têxtil catarinense. Apesar da melhora registrada em variáveis que denotam, em tese, melhor desempenho da mão de 
obra, como a educação, isto não se traduz na remuneração do trabalho. É muito provável que as transformações pelas quais passou esse setor a partir dos anos 1990, com o processo de reestruturação produtiva e inovação tecnológica, tenham modificado as relações de trabalho na indústria têxtil catarinense, refletindo-se em baixos rendimentos e elevada rotatividade empregatícia.

\section{REFERÊNCIAS}

SANTA CATARINA EM DADOS. Florianópolis: FIESC, 2009.

KON, A.; COAN, D. C. Transformações da indústria têxtil brasileira: a transição para a modernização. Revista de Economia Mackenzie, ano 3, n. 3, p. 11-34, 2006.

RAIS. Registros Administrativos. Disponível em: <http://www.rais.gov.br/rais_sitio/index. asp>.

CAGED. Disponível em: <https://granulito.mte.gov.br/portalcaged/paginas/home/home. xhtml>.

NEVES, M. A.; PEDROSA, C. M. Gênero, flexibilidade e precarização: o trabalho a domicílio na indústria de confecções. Sociedade e Estado, Brasília, v. 22, n. 1, p. 11-34, jan./abr. 2007.

SILVA FILHO, L. A.; QUEIROZ, S. N. Indústria têxtil: avaliação empírica do emprego formal em Santa Catarina vis-à-vis o Ceará - 1998/2008. In: ENCONTRO DE ECONOMIA CATARINENSE, 4., 2010, Criciúma. Anais... Criciúma, 2010. p. 19.

SILVA FILHO, L. A.; QUEIROZ, S. N. Recuperação econômica e emprego formal: avaliação para o nordeste brasileiro - 2000/2008. In: CONFERÊNCIA BRASILEIRA DE RELAÇÕES DE EMPREGO E TRABALHO, 4., 2010, São Paulo. Anais... São Paulo: IBRET - USP, 2010. p. 19.

SILVA FILHO, L. A.; QUEIROZ, S. N. Reestruturação produtiva e desestruturação no mercado de trabalho: análise empírica da indústria têxtil da grande Natal. In: ENCONTRO ANUAL DA ASSOCIAÇÃO BRASILEIRA DE ESTUDOS POPULACIONAIS, 17., 2010, Minas Gerais. Anais... Minas Gerais: ABEP, 2010. p. 18. 